This item was submitted to Loughborough's Research Repository by the author.

Items in Figshare are protected by copyright, with all rights reserved, unless otherwise indicated.

\title{
Mutual recognition versus national treatment of standards in a classical monopoly or oligopoly
}

PLEASE CITE THE PUBLISHED VERSION

http://dx.doi.org/10.1628/093245612802921015

PUBLISHER

(C) Mohr Siebeck

VERSION

AM (Accepted Manuscript)

LICENCE

CC BY-NC-ND 4.0

REPOSITORY RECORD

Edwards, T. Huw. 2019. "Mutual Recognition Versus National Treatment of Standards in a Classical Monopoly or Oligopoly”. figshare. https://hdl.handle.net/2134/14640. 
This item was submitted to Loughborough's Institutional Repository (https://dspace.lboro.ac.uk/) by the author and is made available under the following Creative Commons Licence conditions.

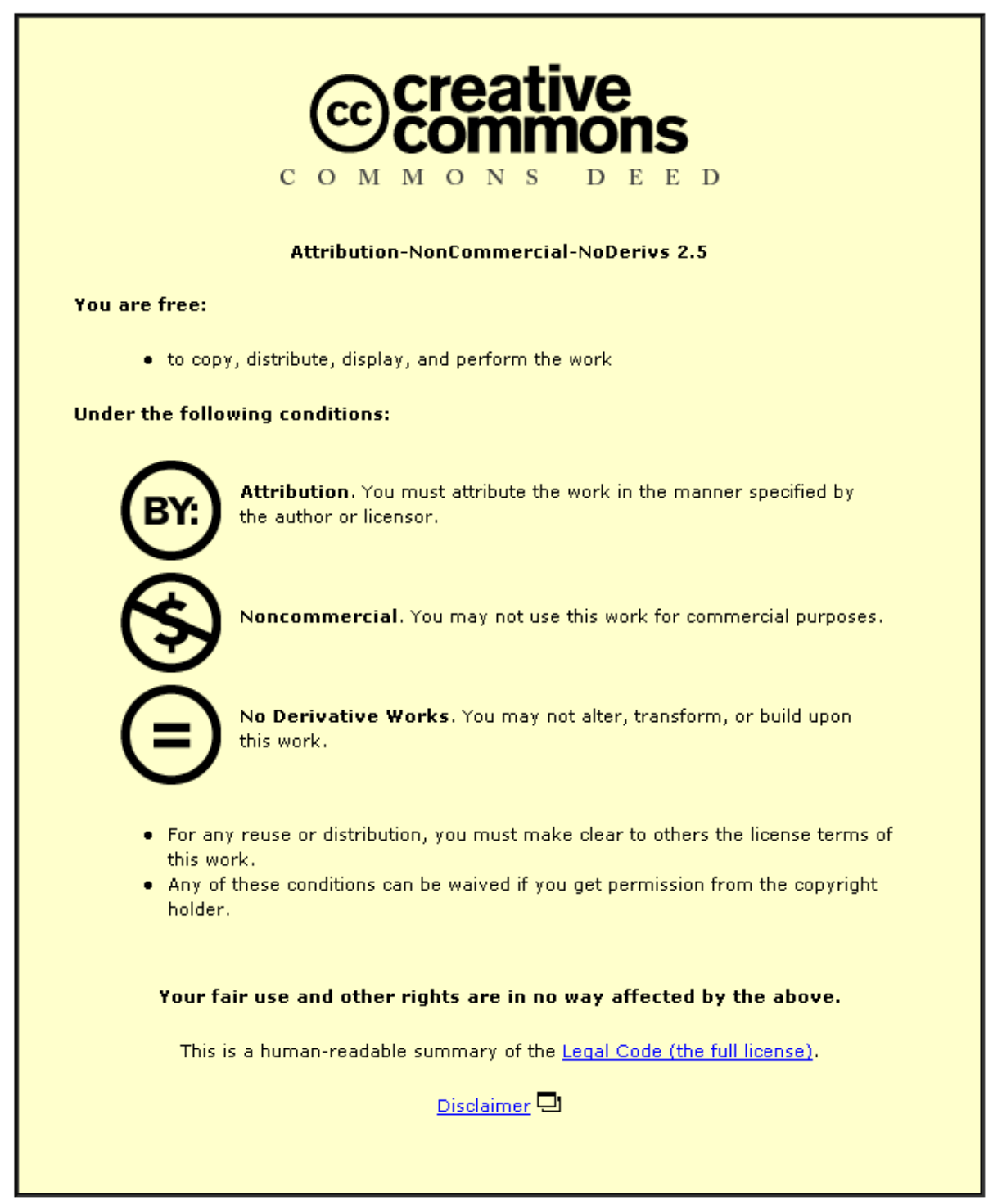

For the full text of this licence, please go to: http://creativecommons.org/licenses/by-nc-nd/2.5/ 


\title{
Mutual recognition versus national treatment of standards in a classical monopoly or oligopoly.
}

\author{
T.Huw Edwards, Loughborough University, UK.* \\ Initial submission: Sept 2009. Final revision submitted June 2011.
}

\begin{abstract}
We examine strategic biases in the international regulation of monopolistic or oligopolistic industries, where a minimum vertical quality standard is imposed on a classical monopoly or duopoly, to correct an undersupply of quality. This differs from Hotelling-based studies, where the aim of minimum quality standards is to correct excessive product differentiation. It also allows examination of unbalanced trade, not considered in previous work. Noncooperative regulators tend to overregulate for profitshifting reasons, though only when producers can vary standards across countries. However, even in this latter case, mutual recognition is only unambiguously welfare-improving when trade is balanced, and it reduces trade flows when quality is taken into account.
\end{abstract}

Keywords: Trade, Regulation, Mutual Recognition

JEL Classifications: F12, F15, C70

\footnotetext{
*I would like to thank Carlo Perroni, David Collie, Geoff Reed, Ben Ferrett, Claudio Piga, Joanna Poyago-Theotoky, Vasileios Zikos, and participants at seminars in Warwick, Nottingham and Loughborough. Any errors are my own.
} 


\section{Introduction}

National standards and regulations ${ }^{1}$ on safety, reliability, or health and environmental grounds underlie many recent trade disputes. There have been disputes over testing and labelling, over the safety of new technologies and over information disclosure and compatibility - for example, the recent stand-off between the European Union and United States over genetically modified foodstuffs, as well as that over Microsoft's software. In response to comparable problems in the past between member states, the EU Single Market initiative has largely concentrated on removing technical barriers to trade (TBTs) ${ }^{2}$ and there have been similar agreements elsewhere (Maskus and Wilson (eds., 2001)).

Liberalising regulations is not straightforward, since they often have a legitimate objective, as acknowledged by the World Trade Organization (1995):

'Members shall ensure that technical regulations are not prepared, adopted or applied with a view to or with the effect of creating unnecessary obstacles to international trade. For this purpose, technical regulations shall not be more trade-restrictive than necessary to fulfil a legitimate objective...'

- WTO Agreement Annex on Technical Barriers to Trade Article 2 $[1995]^{3}$

While the existence of national regulations usually has a legitimate justification, it has long been recognised that their implementation may create TBTs. What is perhaps less well-recognised is that, even when trade is not impeded, regulations may be strategically biased: for example, foreign suppliers may be made to provide higherthan-optimal quality goods. This kind of bias - with strong parallels to the BranderSpencer profit-shifting literature (e.g. Brander and Spencer (1985)) - reduces overall welfare, but is not necessarily trade-reducing.

In this paper, we investigate strategic biases in regulating a monopolistic or oligopolistic industry, where there is a foreign-owned firm. In particular, we compare noncooperative national standard-setting, on the lines of the WTO's 'national treat-

\footnotetext{
${ }^{1}$ Strictly speaking, 'regulations' are applied by governments and 'standards' are voluntarily agreed by industries (Sykes (1995)). We concentrate on the former.

${ }^{2}$ One EU report in 1996 estimated that $76 \%$ of trade between member states was subject to standards, and sectors affected by regulatory trade barriers accounted for $21 \%$ of trade and $29 \%$ of gross value added (reported in OECD [1999]).

${ }^{3}$ Available on http://www.wto.org/english/res_e/booksp_e/analytic_index_e/tbt_01_e.htm\#article2
} 
ment' ${ }^{4}$ with a system of mutual recognition, as favoured by the European Union's 'New Approach'. Under both sets of rules, there are potential strategic biases, though these differ, as in the former approach standards are effectively set by the importing country, while in the latter they are set by the exporting country.

Under a classical monopoly or oligopoly model (Sheshinski (1976)), the primary 'legitimate' motivation for a minimum standard is to correct undersupply of quality. The ways in which producers can raise profits by restricting both the quantity and quality of output are numerous - particularly where we take a broad definition of quality. For example, these could include lack of testing and labelling or use of technological incompatibilities to tie in users to one firm's products. A case in point is the lobbying against genetic modification (GM) of foodstuffs. The response of governments to these will, however, depend upon the geographical structure of the industry: with GM technology, US firms currently tend to dominate. It should be no surprise that European legislators have taken a stricter line than those in North America (Sturm, 2006), leading to a major trade dispute, notably over the separate labelling of GM foodstuffs. It is likely, if higher labelling standards prevail, that trade will be higher in value terms than if they do not, and that this would benefit consumer welfare, though at a cost to profits. ${ }^{5}$ A comparable case is the current antitrust dispute, in which the EU Commission is arguing for much greater disclosure of proprietory information compared to what Microsoft had agreed with US authorities. This would increase compatibility with non-Microsoft products, hence benefiting consumers.

More common, however, may be industries where trade is in both directions, such as aircraft, motor vehicles, food products etc. In these cases, the recent literature (e.g. Boom (1995), or Lutz (1996)) would suggest a bias towards over-regulation under national treatment. However, a couple of cautions are needed. First, we need to distinguish between trade volumes adjusted or unadjusted for quality (the issue of aggregating Mercedes and Skodas): regulations may actually increase trade volumes (or reduce the risk of consumer scares) when adjusted for quality, though at a cost to manufacturers.

The second caution is that the ability of producers to vary the quality of their product across different markets can have important implications for the welfare

${ }^{4}$ National Treatment allows countries to set standards for all goods sold in their own market, but they may not set explicitly different standards for foreign goods.

${ }^{5}$ Nielsen and Anderson [2001] look at one scenario where some of the EU consumer demand is sensitive, but they do not link this to utility, or to the values of traded goods (which tally with utility), which may explain their rather negative assessment of EU policy. 
comparison of various standard-setting games. This is examined in our paper.

The Boom (1995) or Lutz (1996) studies (among others) were based on the Shaked and Sutton (1982) setup, which represents product differentiation spatially, and where the main motivation for regulation is to correct excessive product differentiation. By contrast, this paper uses a classical Cournot setup, where a minimum standard is applied primarily to stop monopoly or oligopoly suppliers undersupplying quality. Nevertheless, if standards can be varied costlessly across countries, there are some strong parallels with the previous studies: there is strategic bias towards overregulation of foreign firms in both models. However, using the classical setup makes it clear that regulations are trade-increasing. ${ }^{6}$ A move from national treatment to mutual recognition may be trade-decreasing (though trade remains above its unregulated level). Secondly, while mutual recognition (MR) is a clear improvement on national treatment (NT) in the case of balanced trade, the welfare effects when production is concentrated in one country (so that trade is unbalanced) are more ambiguous, with the exporting country gaining from a move to MR, while the importing country loses. Overall global welfare increases in some cases and decreases in others.

The alternative case is where firms cannot vary quality standards across markets. This changes results substantially: in fact, remarkably, there is no longer overregulation of a cross-hauling duopoly under NT - instead, standards are automatically set at globally optimal levels. Mutual recognition in this case reduces welfare.

Where there is a monopolist, situated in one country and exporting to the other, and quality is inflexible, the result of national treatment is a bargaining game between the two regulators, with the exporting country trying to lower standards and the importing country trying to raise them. Simulations based upon Nash bargaining with equal weights suggest that the exporting country would gain at the expense of the importing country from the introduction of MR, with a (mostly small) gain to overall global welfare.

The remainder of the paper is as follows: Section 2 sets up a model of vertical quality regulation of a monopoly, and considers the impact of mutual recognition in this unbalanced trade context. Section 3 extends the model to a cross-hauling, Cournot duopoly, while Section 4 examines regulatory standard-setting with mutual recognition and balanced trade. Section 5 examines how these results are affected where it is prohibitively costly for firms to produce at different standards for the two markets. Section 6 looks at pure horizontal protection. Section 7 compares the results with previous studies, and Section 8 concludes.

\footnotetext{
${ }^{6}$ This agrees with Swann et al's (1996) empirical finding that increasing numbers of national standards are correlated with increasing trade.
} 


\section{A model of vertical quality regulation}

Regulatory differences can be horizontal or vertical. The former impose different technologies or incompatible means of achieving a given set of results, such as plug sizes. The latter are where a regulator clearly insists that goods achieve at least a certain minimum standard of safety or performance. In this paper, we concentrate on the vertical type of regulation. We start with a monopoly case, partly because it is simpler, but also because it has relevance to the case of unbalanced trade, where one country exports a good and the other imports it. Subsequently, we extend the model to a cross-hauling duopoly.

\subsection{Basic assumptions in the monopoly case}

We start with the case of a single good, $g$, in a country with identical consumers and a monopoly producer, who may be domestic or foreign. Output has two features: quality, $Q$, and quantity, $Y$, both of which contribute to consumer utility. Because this is a partial equilibrium framework, prices of other goods and incomes are held constant. The consumer gains a direct utility from consuming good $g, U(Q, Y)$, in turn yielding consumer surplus $V$, which will equal $U(Q, Y)-Y P_{y}$, where $P_{y}$ is the price per unit $Y$. Functions are continuous and differentiable, with the usual convexity assumptions, so that $\left\{U^{\prime}(Q), U^{\prime}(Y)\right\}>0,\left\{U^{\prime \prime}(Q), U^{\prime \prime}(Y)\right\}<0$. We also assume diminishing marginal returns to consumption of good $g$. Both $Q$ and $Y$ are produced subject to constant returns to scale: specifically, we assume that the total cost of production, $C$, is a linear function of $Q$ and $Y$, with a scalar $b$ for the relative cost of increasing quality,

$$
C=Y+b Q
$$

where the scalar on $Y$ has been set to unity, without loss of generality.

It is helpful to rewrite this problem, by defining $X=X(Y, Q)$ as a measure of 'quality-adjusted output' (henceforth 'q.a. output'), which aggregates both quality and unadjusted output into a single measure. Utility can then be rewritten as $U=U(X)$, while one can view $Y$ and $Q$ as inputs into the production of $X$. Making the additional restriction that $U$ is homothetic in terms of $Y$ and $Q$, we can choose units of $X$ such that it is produced subject to constant returns to scale. From these assumptions, it follows that $X$ is produced from $Y$ and $Q$ with diminishing marginal returns to substitution, while increasing $X$ yields a positive but diminishing marginal utility for the representative consumer.

Quality-adjusted output, $X$, represents a combination of unadjusted output, $Y$, and quality, $Q$, weighted such that utility can be expressed as a function of $X$ alone. 
$X(Q, Y)$ is defined in units such that it is homogeneous of degree 1 in terms of $Q$ and $Y$.

The basic setup is shown in Figure 1, below. Since $X$ weights $Q$ and $Y$ similarly to how they are weighted in consumer utility, the isoquants for $X$ in Figure 1 correspond to indifference curves for the consumer, as well as to various levels of prices expressed per quality-adjusted unit, which we denote $P$ (so that $P=Y P y / X$ ). A ray through the origin links all the points at which the unit cost of producing $X$ is minimised at a constant $C_{0}$. Moving outwards along this ray, $U^{\prime}(X)$ is declining, so marginal revenue also declines, thus determining the profit-maximising output level for a monopolist, drawn at point $A$, where $X=X_{U}$ here. All other rays through the origin correspond to alternative levels of unit cost, which increase as we move away from the $C_{0}$ ray in either direction.

Figure 1: Consumer indifference curves and the effect of a minimum regulatory quality standard, $Q_{R}$, on quality and unadjusted quantity supplied.

Now assume that a regulator imposes a minimum quality standard, $Q_{R}$, which exceeds the initial quality chosen by the unconstrained firm, $Q_{U}$. As a result, the firm has to raise quality. If it were to keep its q.a. output, $X$, constant, then moving to the new regulatory minimum quality would entail moving from $A$ to $B$ on Figure 1. However, at point $B$, the marginal cost of increasing $X$ is lower than at $A$. Intuitively, we can see this, since, looking along the horizontal line for the minimum quality standard, the higher the line, the more densely-packed are the isoquants crossing it. This implies that a given increase in $X$ can be achieved for less additional input of $Y$. A consequence is that the firm will choose to increase its q.a. output, moving horizontally from $B$ to $C$, lowering average unit costs from $C_{2}$ to $C_{1}$.

More formally, we can derive the following conclusions:

Lemma 1 Imposing a minimum quality standard, $Q_{R}$, where $Q_{R}>Q_{U}$, will lower the marginal cost of increasing $X$.

Proof This follows since $X$ is homogeneous of degree 1 in terms of $Y$ and $Q$, and there are diminishing marginal returns to substitution of $Y$ for $Q$, which implies that the marginal product of $Y$ in terms of $X$ will increase if $Y / Q$ falls. Raising $Q$ means that the initial volume of $X$ can be produced with a lower input of $Y$. Since we assume $X$ has a constant unit cost, raising $\partial X / \partial Y$ implies a falling marginal cost of producing $X .^{7}$ (This is essentially an application of the envelope theorem). Q.E.D.

\footnotetext{
${ }^{7}$ Assuming a Cobb-Douglas/Isoelastic functional form, the proof can also be derived by differentiating equation 1.7 in Appendix 1.
} 
Lemma 2 Raising the minimum quality standard will lead to monotonically increasing quality-adjusted output, up to the point where the firm exits the market.

Proof This follows Lemma 1. Since marginal revenue is assumed to fall monotonically as $X$ rises, the level of $X$ for which marginal revenue equals marginal cost will increase as $Q_{R}$ is raised. Q.E.D.

This situation is analogous to a more familiar problem, where a good is produced with capital and labour. If the monopoly producer is constrained to employ more capital than it would freely choose, it will respond by increasing output (which brings its capital/labour ratio closer to the cost-minimising level). Nevertheless, profits are reduced, due to the higher capital cost. Eventually, of course, the capital costs will be such that the firm will prefer to exit the market, unless it is subsidised. The same happens in our model when quality is raised above a critical threshold.

Lemma 3 Consumer welfare will rise monotonically with an increase in the minimum quality standard, up to the point where the firm exits the market.

Proof This follows from Lemma 2, since a rise in $Q_{R}$ leads to falling marginal costs, inducing the firm to lower q.a. prices, which increase consumer surplus. Q.E.D.

\subsection{Welfare implications}

We compare different regulatory regimes using the suffixes $U$ for unregulated solution, $G$ for globally best regulated solution, $F$ for regulated solution with a foreign firm. Where the firm is foreign, the regulator will seek to maximise consumer surplus, regardless of the cost to profits, subject to the firm not exiting the market.

Figure 2: Imposition of a minimum quality standard on a monopoly.

The solutions are shown schematically in Figure 2. The area bounded by the zero profit condition (thick line) represents the set of potentially profitable solutions. Point $A$, at quality $Q_{U}$, is chosen by an unconstrained monopolist. The ideal solution for welfare would be $W$, which also lies on the cost-minimising ray through the origin, though further out. However, a regulator could only force the firm to produce at $W$ by regulating both price and output. If we are assuming the regulator can only set a minimum standard for quality, then the best he can do by raising quality is to force the firm upwards along its response function (the thick dashed line). Point $G$ represents the global optimum achievable by quality regulation, where the sum of producer and consumer surplus is maximised. $F$ represents the regulator's preferred solution where the firm is foreign. $G$ will lie above the unregulated monopolist's q.a. output, since the initial marginal cost to the firm from deviating from its 
cost-minimising mix of $X$ and $Q$ is infinitessimal, while the induced increase in output brings a gain to consumers. However, without making further assumptions, we cannot determine for certain whether $G$ lies within the feasible area, in terms of nonnegative profits, or whether (as we have drawn at $G G$ ), it lies outside, so the firm would exit without a subsidy.

To compare these points more formally, we restrict the analysis to a more limited functional form (though many of the conclusions will carry over to a wide range of well-behaved functional forms). We assume $X$ is a Cobb-Douglas aggregate of $Y$ and $Q$

$$
X=Y^{\beta} Q^{1-\beta}
$$

where $\beta \in(0,1)$. Also, utility is assumed to be isoelastic: $U=\gamma X^{\eta}$, where $\eta \in(0,1)$. Since the consumer will equate price to marginal utility, consumer surplus

$$
V=\gamma(1-\eta) X^{\eta}
$$

A series of equations defining the solutions to this model is shown in Appendix 1 Table $1^{8}$

Comparing the outcomes, we derive three propositions:

Proposition 1 The regulatory standard for a foreign monopolist under NT is higher than that for a domestic monopolist, and both are higher than the firm itself would choose.

Proof Comparing $Q_{G}$ in equation Appendix 1 equation (1.11) with $Q_{U}$ in (1.9), where $k_{2}$ and $k_{3}$ are defined in Appendix 1 Table 1,

$$
\frac{Q_{G}^{1-v}}{Q_{U}^{1-v}}=\frac{k_{2}+1-k_{3}}{1-k_{3}}>1==>Q_{G}>Q_{U} .
$$

Comparing $Q_{F}$ in Appendix 1, equation (1.13) with $Q_{G}$,

$$
Q_{F}^{1-v}-Q_{G}^{1-v}=\frac{\left(1-k_{3}\right) k_{1}}{b}-\frac{\left(k_{2}+1-k_{3}\right) v k_{1}}{b} .
$$

Since $k_{1}$ and $b$ are both positive, this will exceed zero if $(1-v)\left(1-k_{3}\right)>v k_{2}$. Substituting in for $v, k_{2}$ and $k_{3}$, it can be shown to be equivalent to $\eta<1$. But we

\footnotetext{
${ }^{8}$ Unlike some models (Ronnen (1991)), we explicitly derive consumer surplus, rather than just focusing on consumer price, since we wish to be able to add it to producer surplus and derive total welfare, $W$.
} 
have already assumed $\eta \in(0,1)$, so it will always hold, and $Q_{F}>Q_{G}$. Ranking th e various standards, $Q_{F}>Q_{G}>Q_{U}$. Q.E.D.

It is also worth considering the implications of a mutual recognition agreement in the case of a monopoly.

Proposition 2 Mutual recognition in the presence of a monopoly will result in a reduction in quality and quality-adjusted trade volumes compared to national treatment.

Proof Where the two countries are identical in size and consumer preferences, the exporter's regulator will seek to maximise $W_{X}=V_{X}-2 \Pi_{X}$, where subscript $X$ refers to the exporting country, and $V$ and $\Pi$ conform to Appendix 1 equations (1.5) and (1.8). The first order condition for maximising $W_{X}$ with respect to $Q_{X}$ is

$$
\frac{\partial W_{X}}{\partial Q_{X}}=0==>Q_{X}^{1-v}=\left(\frac{k_{2}}{2}+1-k_{3}\right) v \frac{k_{1}}{b} .
$$

Comparing (6) with Appendix 1 equations (1.9) and (1.11), we can see that $Q_{X}^{1-v}$ lies midway between $Q_{U}^{1-v}$ and $Q_{G}^{1-v}$, being above the former and below the latter (since $v<1$ ). Lemma 2 shows that higher quality standards raise the quantity supplied. We also note from (1.3) that quality-adjusted output $X=\Omega^{\beta /(1-\beta \eta)} Q_{X}^{v / \eta}$, which is monotonically increasing with respect to quality $Q_{X}$ (at least over the range where the imposed constraint is binding on the firm). Consequently, if the exporting country sets lower standards than under NT, quality-adjusted output will also be lower.

We can deduce that:

Proposition 3 The introduction of mutual recognition in place of national treatment in the presence of a monopoly, will result in a reduction in consumer utility in both the importing and the exporting country, but with a gain to the monopolist's profits. Overall, the exporting country gains and the importing country loses.

Proof Proposition 3 follows since lower quality standards (so long as they are still above $Q_{U}$ ) benefit the producer at the expense of consumers (inverting Lemma 3). Under NT, the importing country chooses quality, while under MR, the exporting country chooses quality to maximise its welfare. Q.E.D.

[Note, the case where there is a monopoly firm and quality standards cannot be varied across markets is complicated, involving bargaining - see Section 5.2 below. The results of Proposition 3 will normally carry across, however]. 
The overall sign of the net effect on global welfare of a move to MR is not straightforward to determine. Figure 3, below, indicates the results of numerical simulations over a wide variety of parameter values. Mutual recognition reduces global welfare in cases where $\beta$ is low-to-middling, particularly when $\eta$ is high. This basically corresponds to those cases where a significant weight in utility is given to quality (note that NT results in higher quality than MR) and there is a high degree of monopoly power. In other cases, welfare is reduced, particularly where $\eta$ is low, which leads to low monopoly power, as measured by firms' markup over marginal cost.

Figure 3: effect on global welfare of moving to national treatment from mutual recognition, in the case of an exporting monopolist, given flexible product standards.

\section{National treatment in a duopoly with balanced trade}

We now extend the model to a duopoly. The analysis follows in the tradition of profit-shifting duopoly models (see the survey in Brander (1995), or Brander (1981), or Brander and Spencer (1985)). We concentrate on two identical countries, trading reciprocally. We use a two stage setup: in the first stage, each national regulator sets the standards to apply in its market (or, in the case of MR, to its own producers in both markets). In the second stage, the firms respond, competing on the basis of Cournot conjectures. The regulators in the first period are able to predict accurately the outcome of this second-period subgame, and to exploit first-mover advantage to benefit their 'own' firm and consumers at the expense of the foreign firm.

The model is solved subject to three possible sets of rules, and the outcomes compared:

i) NT: the regulator in a country sets the standard for all goods sold in his market.

ii) A MR agreement: the quality standard for imports is set by the regulator in the country of origin, rather than that of the importing country.

iii) Full cooperation between the regulators, to set a globally optimum harmonised standard.

In this section, we assume that firms can costlessly set standards separately for each market, so that, with NT, the regulator in one country can set standards regardless of the behaviour of the other country's regulator. Consequently, one can ignore any strategic interaction between the regulators. By contrast, where there is MR, the foreign regulator can determine the product quality of its exporting firm: 
this creates a higher-level regulatory game between the two countries, for which we derive the subgame-perfect Nash equilibrium. Section 5, below, discusses the effect of making it prohibitively costly for firms to vary the quality supplied to different markets.

\subsection{The duopoly model setup}

The industry contains two identical firms, $f=1$ and 2 , set in countries $c=1$ and 2 respectively. All consumers in both countries have identical tastes, and the firms produce outputs which are perfect substitutes, with identical production functions. As before, consumers' utility in country 1 is a homothetic function of quality-adjusted consumption, which we now denote $Z_{1}$, where $Z_{1}=X_{1,1}+X_{2,1}$, and $X_{1,1}$ and $X_{2,1}$ are aggregates of quality, $Q_{f, c}$ and unadjusted quantity, $Y_{f, c}$. The production cost of $X, C_{f, c}$, is a linear function of $Y_{f, c}$ and $Q_{f, c} \cdot{ }^{9}$ We assume here that firm $f$ chooses its quality to supply to each market separately. For simplicity, we drop the country superscript from this point, except where specifically needed.

There is a strong analogy with the monopoly case, although an unregulated Cournot duopoly produces a higher level of q.a. output, $X_{U}$, and a higher level of output for any level of regulation, compared to a monopolist. When a firm is unregulated, marginal cost is constant, as given by Appendix 1 (1.7). Likewise, when country 1 sets a higher standard than the unregulated duopoly would choose, marginal costs for firm $f$ fall as $Q / X_{f}$ rises. The quality standard and output levels chosen by the unregulated duopoly are still suboptimal, at point $A^{\prime}$ rather than $W$, on Figure 4, using the prime to denote the noncooperative Cournot duopoly case, and there is a potential benefit from regulation. However, there are two differences. First, we must now distinguish between two regulatory outcomes: the one where both firms are domestic (which is the global best achievable by quality regulation alone, $G^{\prime}$ ), and the other where the regulator ignores the foreign firm's profits, which would potentially lead to a higher standard. The other difference is that, since the duopoly has lower profits than an unregulated monopoly, its profits are eliminated more quickly as standards are raised (at quality $Q_{0}^{\prime}$ ). This is shown in the diagram as constraining the quality standard $Q_{F}^{\prime}$ which the regulator can set at $E^{\prime}$ rather than $E^{\prime \prime}$ as he would prefer.

${ }^{9}$ Strictly speaking, if the values of scale parameters in equation (1) were invariant with the number of firms, the smaller firms in a duopoly case would be producing a lower quality than the monopolist in the first case. However, a slightly modified formulation (eg where costs are a function of output and quality per plant, and the number of plants) would return the model to the classical features where a monopoly results in lower quality and quantity. 
Figure 4: Imposition of a minimum standard on a Cournot duopoly.

To proceed further, we again need to make some more precise functional form restrictions. We assume, once again, that demand for q.a. output is isoelastic ${ }^{10}$, so that consumer surplus in country 1 is given by

$$
V_{1}=\gamma(1-\eta) Z_{1}^{\eta}
$$

which is very similar to (1).

Since both countries are analogous, we concentrate on country 1, ignoring national subscripts, and dropping the prime for the Cournot case. We follow the CournotNash assumption that $f$ chooses $X_{f}$ as a response to its conjecture of its rival's output. ${ }^{11}$ If we denote the firms' respective marginal costs $M C_{1}$ and $M C_{2}$, then the Cournot-Nash equilibrium is defined by the following equations for total output, $Z$, and for relative output of the two firms

$$
\begin{gathered}
Z=X_{1}+X_{2}=\left[\frac{M C_{1}+M C_{2}}{\gamma \eta(1+\eta)}\right]^{\frac{1}{\eta-1}}, \text { and } \\
\theta=\frac{X_{2}}{X_{1}}=\frac{M C_{1}-\eta M C_{2}}{M C_{2}-\eta M C_{1}},
\end{gathered}
$$

Note that $X_{1}=Z /(1+\theta)$ and $X_{2}=\theta Z /(1+\theta)$. These conditions determine the market outcome of the Cournot subgame between the firms. ${ }^{12}$ Where standards are set noncooperatively, and the firms are symmetric in costs, then we can concentrate on the symmetric equilibrium where $\theta=1$ and $X_{1}=X_{2}$.

From the above equations, we can deduce the equilibrium properties of the model. These are summarised in Appendix 1 Table 1.2.

First note:

Lemma 4 A regulated duopoly will sell more quality-adjusted output than an unregulated duopoly, and this output rises monotonically with the quality standard.

\footnotetext{
${ }^{10}$ See Neary [1994]. The choice of $0<\eta<1$ in this paper ensures that, in a symmetric model, the two goods are strategic substitutes.

${ }^{11}$ The alternative Bertrand-Nash duopoly is uninteresting unless firms' output is differentiated.

${ }^{12}$ Equation (9) yields non-negative values for $X_{1}$ and $X_{2}$ as long as the numerator and denominator carry the same sign, which will be the case if $1 / \eta>M C_{2} / M C_{1}>$ $\eta$.This implies that either $M C_{2}$ and $M C_{1}$ are close in value or that $\eta$ is small.
} 
Proof If $Q_{R}$ is set exogenously by the regulator, then Appendix 1, equation (2.2) and the equivalent equation for firm 2 show that combined output of the two firms is an isoelastic function of the quality standard set by the regulator. Since $\beta, \beta \eta \in(0,1)$, we can deduce that $\partial Z / \partial Q$ is positive. Q.E.D.

Analysis with no breakeven constraint.

There is a strong analogy to regulation of a monopoly, except that a duopoly sets somewhat higher output levels. There follows

Lemma 5 Consumer surplus with a quality regulated Cournot duopoly rises monotonically with the minimum quality standard.

Proof This follows since sales rise monotonically with the minimum quality standard (Lemma 4), and utility rises monotonically with sales (Appendix 1, (2.4)). Q.E.D.

Lemma 6 If there is no constraint that firms' profits exceed zero, then regulators under national treatment will always set standards higher than the global optimum standard.

Proof Comparing Appendix 1 equations (2.7) with (2.9), where $K_{2}$ and $K_{3}$ are constants as defined in Appendix 1 Table 2:

$$
\frac{Q_{F}^{1-v}-Q_{G}^{1-v}}{Q_{G}^{1-v}}=\frac{\frac{K_{2}}{2}}{\frac{K_{2}}{2}+1-K_{3}},
$$

which is positive given $K_{2}>0$ and $1-K_{3}>0$. Since $v \in(0,1)$, this implies that $Q_{F}>Q_{G}$. Q.E.D.

\section{Analysis with a breakeven constraint}

The standard, $Q_{0}$, at which profits fall to zero, is given by Appendix 1, equation (2.10). This always exceeds $Q_{G}$ for ranges of $\beta$ and $\eta$ between 0 and $1 .^{13}$ However, $Q_{0}$ may constrain $Q_{F}$, depending upon parameter values:

Lemma 7 Unless $\beta$ is sufficiently high relative to $\eta$, the quality standard set under NT will either be constrained to the highest standard at which firms do not make a loss, or the firms will have to be subsidised.

\footnotetext{
${ }^{13}$ Proof available.
} 
Comparing Appendix 1 (2.7) and (2.10), we can say that $Q_{F}$ will exceed $Q_{0}$ if and only if $\left(1-K_{3}\right) K_{1} / b<\left[K_{2}+1-K_{3}\right] v K_{1} / b$, which is equivalent to the condition that

$$
\beta<\frac{2}{3-\eta}
$$

Most combinations of $\{\beta, \eta\}$ between 0 and 1 satisfy (3) - see Figure 5, below and we would expect the breakeven constraint to limit standard setting in these circumstances. Q.E.D.

Figure 5: combinations of $\beta$ and $\eta$ for which the regulatory standard is constrained.

The constraint is not binding only where $\beta$ is high (i.e. relatively little value is placed on quality) and $\eta$ is low (which implies elastic demand, and hence less monopolistic distortion in the absence of regulation).

The lemmas above can be summarised as:

Proposition 4 With a symmetric Cournot duopoly and national treatment, the global optimum standard will be greater than the unregulated quality. The standard chosen by the regulator in a noncooperative subgame-perfect Nash equilibrium will be above the global optimum, but the extent to which it exceeds the global optimum will be restricted if the condition in (11) does not hold, so long as there are no subsidies.

The analysis in this section potentially casts a new light on the best-known cross-hauling duopoly, the Boeing-Airbus case. (Pavcnik (2002). Irwin and Pavcnik (2004)). Both firms are recipients of overt and covert subsidies, which are commonly interpreted as being a war for market-share. However, safety and environmental concerns are crucially important, so regulation is likely to be an important item in driving costs. While subsidies may well be excessive, this may potentially reflect excessively high regulatory quality standards, to benefit consumers (in terms of extra safety) at the expense of the foreign firm.

\section{Analysis with mutual recognition}

We now examine a mutual recognition agreement. The two country regulators play a standard-setting game, taking into account the anticipated result of changes in their national standard upon the outcome of the Cournot subgames between the firms in both national markets. MR changes these games, in that each national regulator is 
now assumed to be able to set the standard for its own firm in both markets, but cannot directly influence the standard the foreign firm sets.

Comparison with either the global optimum standard or the NT standard is complicated, since there a number of contradictory effects. These stem from noting that national welfare

$$
W=V+S \Pi-F C
$$

where $V$ is domestic consumers' utility, $S$ is the domestic firm's market share and $F C$ is the domestic firm's fixed cost. Hence, if we differentiate (12) with respect to $Q$

$$
\frac{\partial W}{\partial Q}=\frac{\partial V}{\partial Q}+S \frac{\partial \Pi}{\partial Q}+\Pi \frac{\partial S}{\partial Q}-\frac{\partial F C}{\partial Q} .
$$

The terms of the differential are, respectively, the consumer surplus effect, the nation's share of the producer surplus effect, the profit-shifting effect and the effect on fixed costs. These are summarised in Table 1, below.

\begin{tabular}{||lllll||}
\hline \hline $\begin{array}{l}\text { Effect of raising a } \\
\text { minimum quality } \\
\text { standard }\end{array}$ & $\begin{array}{l}\text { Effect on } \\
\text { national welfare }\end{array}$ & $\begin{array}{l}\text { Rel. effect } \\
\text { on global } \\
\text { v national }\end{array}$ & MR \\
Consumer surplus $\frac{\partial V}{\partial Q}$ & $\begin{array}{l}\text { welfare } \\
\text { + but declining }\end{array}$ & $x 4$ & $x 2$ & $x 1$ \\
$\begin{array}{l}\text { Tot prod surplus } \\
\text { excl fixed cost } S \frac{\partial \Pi}{\partial Q}\end{array}$ & $\begin{array}{l}\text { declining }<\frac{\partial F C}{\partial Q} \\
\text { Profit shifting } \Pi \frac{\partial S}{\partial Q}\end{array}$ & $x 4$ & $x 1$ & $x 2$ \\
$\begin{array}{l}\text { (Minus) Quality-related } \\
\text { fixed cost per }\end{array}$ & $\begin{array}{l}\text { negative } \\
\text { firm/market } \frac{\partial F C}{\partial Q}=b\end{array}$ & & - & \\
\hline \hline
\end{tabular}

Table 1: summary comparison of the effects of raising minimum quality standards under different regulatory regimes.

Key differences are that, under NT, domestic consumers benefit from the rise in quality of both firms' output, but the loss to the foreign firm (at the margin) is ignored. Under MR, consumers only benefit from the rise in quality for domesticallyproduced goods (so the marginal consumer benefit is halved), but the cost of raising the quality of exports is borne by the domestic producer (while the gain to foreign consumers is ignored). However, there is a profit-shifting effect, on the lines of 
Brander-Spencer, whereby the quality increase raises the market share of country 1's goods in both markets (home and export), increasing profit.

The standard set by regulator 1 in each case are summarised as:

$$
\begin{gathered}
\text { global optimum: } \frac{\partial W_{G}}{\partial Q_{G}}=0=>\frac{\partial V}{\partial Q_{G}}+\frac{\partial \Pi}{\partial Q_{G}}=b \\
\operatorname{NT}: \frac{\partial W_{1 N}}{\partial Q_{1 N}}=0=>2 \frac{\partial V}{\partial Q_{1 N}}+\frac{\partial \Pi}{\partial Q_{1 N}}=b \\
\text { MR: } \frac{\partial W_{M}}{\partial Q_{1 M}}=0=>\frac{\partial V}{\partial Q_{1 M}}+2 \frac{\partial \Pi}{\partial Q_{1 M}}+2 \Pi \frac{\partial S_{1}}{\partial Q_{1 M}}=2 b .
\end{gathered}
$$

Comparing the global optimum with the NT, for any given value of $Q_{1}$, the left hand side of the NT equation is greater than for the global optimum by $\partial V / \partial Q_{1 N}$. Since marginal benefits of raising standards decline as $Q_{1}$ is raised, this implies the value of $Q_{1}$ which satisfies equation (5) will be greater than that which satisfies (14), which we have already established more formally $\left(Q_{1 N}>Q_{G}\right)$. A comparison of the solution to (6) with those for (4) and (5) is more complicated, because there is a profit-shifting effect when standards are set according to MR (and this profit shift will depend on the rival regulator's standard). However, if we concentrate on a symmetric equilibrium (where both regulators set the same standard), then comparison is a little more straightforward. Rewriting (4) as

$$
\frac{\partial W_{G}}{\partial Q_{G}}=0=>2 \frac{\partial V}{\partial Q_{G}}+2 \frac{\partial \Pi}{\partial Q_{G}}=2 b,
$$

we see that, for any given level of global standards

$$
\frac{\partial W_{M}}{\partial Q_{1 M}}-\frac{\partial W_{G}}{\partial Q_{G}}=2 \Pi \frac{\partial S_{1}}{\partial Q_{1 M}}-\frac{\partial V}{\partial Q_{G}} .
$$

Essentially, this tells us that, if we initially look at global optimum standards, where $\partial W_{G} / \partial Q_{G}=0$, regulator 1 under MR will want to raise standards if and only if the profit-shifting effect outweighs the effect of ignoring the gain in quality to foreign consumers.

Strictly, to solve this problem, we need to model it in terms of comparative statics, solving for the equilibrium. Nevertheless, the implication of (5) is that the outcome of the MR setup depends critically upon the profit-shifting effect, which means that we need to look carefully at the modelling of regulators' behaviour and market shares.

I assume that each regulator will act on the conjecture that the other regulator's strategy (and hence, the foreign firm's standard) is exogenous: an equilibrium is 
where actual standards equal conjectured ones for both countries. An equilibrium can also be seen as the point of intersection of the two regulators' reaction functions. Where these are monotonically-sloping, there will be only one point of intersection, at a symmetric equilibrium where $Q_{1}=Q_{2}$.

Let us start by considering the equations governing the reaction functions of the two regulators. Regulator 1 will assume regulator 2 will maintain a constant standard, so $Q_{2}^{c}=\bar{Q}_{2}^{c}$. He will then choose $Q_{1}$ to maximise domestic welfare ${ }^{14}$. $W_{1}=V_{1}+2 R_{1 c}-2 V C_{1 c}-2 b Q_{1}$, where the subscript $c$ notes firm 1's revenue or costs in any one market. The solution to this optimisation problem depends crucially upon the effect of altering $Q_{1}$ upon the two firms' outputs. First, consider how firm 1's market share ( $S_{1}$, which is the same in both markets) will alter with respect to its quality (keeping $\bar{Q}_{2}^{c}$ constant). If the ratio of marginal costs, $M C_{2} / M C_{1}$, is denoted $M$, then we can derive from (2) that

$$
S_{1}=\frac{M-\eta}{(1+M)(1-\eta)}
$$

and so

$$
\frac{\partial S_{1}}{\partial M}=S_{1}^{2} \frac{1-\eta^{2}}{(M-\eta)^{2}} .
$$

Noting that $\eta<1, \partial S_{1} / \partial M$ is positive as long as $M$ is greater than $\eta$, and decreases as $M$ rises. Note from (7) that $S_{1}$ reaches 1 when $M$ reaches $1 / \eta$. Also, from the relationship of marginal costs to output, we can derive that

$$
\begin{gathered}
M=\left(\frac{Q_{1}\left(1-S_{1}\right)}{\bar{Q}_{2}^{c}}\right)^{\frac{1-\beta}{\beta}} . \\
\frac{\partial M}{\partial Q_{1}}=\frac{(1-\beta)(M-\eta)(1-\eta M)}{(1-\eta M)\left(1-\beta \eta M^{-1}\right)+\eta((1-\beta)(M-\eta)) Q_{1}^{*}} .
\end{gathered}
$$

This leads to

Lemma $8 S_{1}$ is monotonically upward-sloping with respect to $Q_{1}$, reaching 1 when $Q_{1}=1 / \eta$.

Proof Note that $\partial M / \partial Q_{1}=0$ when $M=\eta$ or $M=1 / \eta$. If we therefore confine ourselves to the range $\eta<M<1 / \eta$, given $\beta \eta \in(0,1)$, then the numerator of $(7)$ is positive, as are $(1-\eta M),\left(1-\beta \eta M^{-1}\right)$ and $(1-\beta)(M-\eta)$. It follows that, over this range, $\partial M / \partial Q_{1}>0$. Since from the chain rule $\partial S_{1} / \partial Q_{1}=\left(\partial S_{1} / \partial M\right)\left(\partial M / \partial Q_{1}\right)$, and both of these are positive over the range $\eta<M<1 / \eta$, then $S_{1 M}$ is monotonically

\footnotetext{
${ }^{14}$ Regulator 2's decision is a mirror-image of this.
} 
upward-sloping in terms of $Q_{1}$, curving off as $S_{1 M}$ approaches 1 . This is confirmed by numerical simulation. Q.E.D.

\section{Derivation of symmetric equilibrium values}

Given the complexity of some of the differentials, we concentrate on symmetric equilibria. ${ }^{15}$ A symmetric, pure strategy equilibrium is one where $Q_{1}=Q_{1}^{c}=Q_{2}=$ $Q_{2}^{c}$. Because it is symmetric, we can solve it just looking at country 1's decision as a response to country 2's standard setting. Consequently, we start by examining the locus of symmetric quality regulations, where $Q_{1}=\bar{Q}_{2}^{c}$. A symmetric Nash equilibrium is a point on this locus where neither regulator will wish to adjust quality (assuming the other regulator's standard is constant). To be practicable, such an equilibrium must also lie above the standard the firms would independently set, and below the level at which they exit the market. Concentrating on regulator 1's decision: he will assume regulator 2 will maintain the initial standard, $\bar{Q}_{2}^{c}$. Regulator 1 will then choose a new standard $Q_{1}$ in order to maximise his conjecture of welfare in country 1 . In equilibrium, both national markets will be split equally between the firms. We can easily simplify (6)-(7) substituting $M=1$ and $S_{1}=1 / 2$. This allows us to derive the result that

$$
\begin{aligned}
\frac{\partial S_{1}}{\partial Q_{1}} & =\frac{1}{4} \frac{K_{4}}{Q_{1}}, \\
\text { where } K_{4} & =\frac{\left(1-\eta^{2}\right)(1-\beta)}{(1-\eta)((1-\beta \eta)+\eta(1-\beta))}>0 .
\end{aligned}
$$

In addition, note that the marginal effect on total sales of increasing just $Q_{1}$ is half that of increasing both countries' standards simultaneously. The latter has already been shown to be an isoelastic function of quality, so we can write:

$$
\frac{\partial Z_{1}}{\partial Q_{1}}={\frac{K^{\prime} \bar{Q}^{\frac{v-\eta}{\eta}}}{2}}
$$

where $K^{\prime}=(v / \eta) \Psi^{\beta /(1-\beta \eta)} 2^{(1-2 \beta) /(1-\beta \eta)}$. Having determined the marginal effects of changing $Q_{1}$ on total sales and on the firms' shares, it is not difficult to derive the marginal effects on firm 1's revenue and variable cost (in each market) and on consumer surplus. ${ }^{16}$ Taken together, these equations define a symmetric equilibrium

${ }^{15}$ The equivalent equations for the more general case, which allows for asymmetric equilibria, are available on request. Numerical checks on a range of values of $\beta$ and $\eta$ between 0.3 and 0.7 confirmed that the model has an unique, stable solution within the feasible range with positive output.

${ }^{16}$ Available on request. 
for quality in the MR case. While it is possible to derive a reduced form from these equations and solve it for the equilibrium value of $Q_{1}=\bar{Q}_{2}^{c}$, which we denote $\bar{Q}$, it is not particularly informative in this case, which is why we prefer to derive a solution by numerical means.

\subsection{Numerical analysis}

It is not possible to derive meaningful comparative static solutions for the subgame perfect Nash equilibrium with MR by analytical means. Consequently, we proceed by numerical simulation. Tables 2 and 3 summarise the degree to which the constrained quality under NT and the quality under MR exceed the global optimum in these simulations.

\begin{tabular}{||lllllll||}
\hline \hline$\frac{\tilde{Q}_{N}-Q_{G}}{Q_{G}}$ & $\eta=$ & & & & & \\
$\beta=$ & 0.3 & 0.4 & 0.5 & 0.6 & 0.7 & 0.8 \\
\hline 0.3 & $0.15^{*}$ & $0.13^{*}$ & $0.10^{*}$ & $0.08^{*}$ & $0.06^{*}$ & $0.04^{*}$ \\
0.4 & $0.23^{*}$ & $0.19^{*}$ & $0.16^{*}$ & $0.13^{*}$ & $0.10^{*}$ & $0.07^{*}$ \\
0.5 & $0.34^{*}$ & $0.29^{*}$ & $0.24^{*}$ & $0.19^{*}$ & $0.14^{*}$ & $0.10^{*}$ \\
0.6 & $0.50^{*}$ & $0.43^{*}$ & $0.35^{*}$ & $0.28^{*}$ & $0.21^{*}$ & $0.14^{*}$ \\
0.7 & $0.77^{*}$ & $0.66^{*}$ & $0.54^{*}$ & $0.43^{*}$ & $0.32^{*}$ & $0.22^{*}$ \\
0.8 & 0.93 & 0.91 & $0.91^{*}$ & $0.72^{*}$ & $0.54^{*}$ & $0.36^{*}$ \\
\hline \hline
\end{tabular}

Table 2: difference between standards under national treatment and the global optimum standard, taking account of the nonnegative profit constraint. ${ }^{17}$

\begin{tabular}{||lllllll||}
\hline \hline$\frac{Q_{M}-Q_{G}}{Q_{G}}$ & $\eta=$ & & & & & \\
$\beta \stackrel{=}{=}$ & 0.3 & 0.4 & 0.5 & 0.6 & 0.7 & 0.8 \\
0.3 & 0.01 & 0.01 & 0.02 & 0.01 & 0.01 & 0.00 \\
0.4 & 0.02 & 0.02 & 0.02 & 0.02 & 0.02 & 0.01 \\
0.5 & 0.02 & 0.03 & 0.03 & 0.03 & 0.02 & 0.01 \\
0.6 & 0.03 & 0.04 & 0.04 & 0.04 & 0.03 & 0.02 \\
0.7 & 0.04 & 0.04 & 0.05 & 0.05 & 0.05 & 0.04 \\
0.8 & 0.05 & 0.06 & 0.06 & 0.06 & 0.06 & 0.05 \\
\hline \hline
\end{tabular}

\footnotetext{
$17 *$ denotes nonnegative profit constraint is binding.
} 
Table 3: Difference between the standard set under mutual recognition (taking account of the nonnegative profit constraint) and the global optimum standard.

A more general summary of the conclusions of the simulations carried out is as follows:

First, Table 2 confirms the conclusions of the theoretical analysis that, in all cases, $Q_{N}>Q_{G}>Q_{U}$. $Q_{U}$ varies between 55 and 62 per cent of the global optimum standard, $Q_{G}$. In all cases examined, the zero profit quality, $Q_{0}$ exceeds the global optimum, $Q_{G}$. In addition, the nonnegative profit constraint, $Q_{0}$ will constrain the local regulator under NT, except where $\beta$ is relatively high and $\eta$ relatively low.

Table 3 shows that, In all the cases examined, $Q_{M}>Q_{G}$. This indicates that the profit shifting effect outweighs any gain to profits from cutting quality sold to foreigners. However, this difference is marginal, and in practice the difference between $Q_{M}$ and $Q_{G}$ is very small in all cases. We would therefore expect MR to be welfare-improving compared to NT. However, consumers are worse off. Note that $Q_{0}$, does not constrain the quality set under MR in any of the cases examined.

Figure 6, below, shows the comparative welfare gain from moving from NT to MR. In all cases, welfare under MR lies less than 0.1 per cent below the global optimum.

Figure 6: Per cent gain in global welfare from moving to mutual recognition from noncooperative national treatment.

Comparing Figure 6 to the monopoly case (Figure 3), note that in a symmetric duopoly MR is always welfare-increasing compared to NT. However, as in the monopoly case, $\mathrm{MR}$ is most beneficial when $\beta$ is high, implying that consumers place relatively little value on quality (so that the lower quality standards in equilibrium under MR have less effect on consumer welfare).

As with any numerical simulations, a word of caution is needed: it is not possible to confirm that the results carry over to parameter values other than those investigated. Due to the nonlinearity of the model, values of $\beta$ or $\eta$ less than 0.3 or greater than 0.8 could not be investigated. Also, some different functional forms might give qualitatively different results. ${ }^{18}$

Finally in this section, it is worth noting that, in common with most of the literature on national treatment and mutual recognition, this paper has assumed the

\footnotetext{
${ }^{18}$ In principle, if regulators' reaction functions are backward-bending, then it is possible they intersect again at some point other than the symmetric equilibrium. However, numerical simulations for a variety of combinations of $\{\beta, \eta\}$ suggest near-linear reaction functions.
} 
countries are identical in terms of size and representative consumers' tastes. Extension to cover all possible asymmetries of the countries would probably be beyond the scope of this paper. ${ }^{19}$

\section{$5 \quad$ Quality rigidities}

The previous sections have assumed that firms can costlessly change quality between the two national markets, in response to national regulators' specifications. This is probably not a realistic assumption. An alternative is to assume that the firm must set the same standard for both markets, since the cost of varying standards is prohibitive.

\subsection{Duopoly}

Consider first the duopoly case. If standards are set under MR, then the analysis is unchanged from that in Section 4. above. This is because, under MR, a firm always sets a single standard anyway, determined by its own national regulator. By contrast, if firms cannot vary quality across markets, then the effects of NT upon standard-setting are interesting. We assume that regulator 1 is setting a standard, and that regulator 2 has not set a higher standard (so limiting regulator 1's freedom to affect local standards). Regulator 1 will choose a standard, $Q_{N}$, to maximise

$$
W_{1 N}=V_{1 N}+R_{1 N}+R_{2 N}-2 C_{1 N},
$$

where $R_{1 N}$ is firm 1's revenue in its home market and $R_{2 N}$ is its revenue in the export market. Note the final term in (22) - if regulator 1 increases its standard, it imposes extra cost on firm 1's sales in both markets. In both cases (unlike MR), if regulator 1 raises the standard, both firms have to raise quality in both markets.

Compare this with the decision made by a single global regulator to maximise global welfare. In this case, assuming symmetric costs and demand functions in the two countries, he is maximising

$$
W_{G}=2 V_{1 G}+2 R_{1 G}+2 R_{2 G}-4 C_{1 G},
$$

and comparing (8) with (9) we derive the result

$$
Q_{N}=Q_{G}
$$

\footnotetext{
${ }^{19}$ If we allowed taste parameter $\beta$ to vary, then under mutual recognition, the country with greater taste for quality would desire to set a higher standard for its firm in both markets (so the equilibrium would be asymmetric).
} 
Effectively, in (8), regulator 1 is considering the consumer surplus of half the World's consumers, compared to the profit of half the World's producers, in a model where both firms have to produce to the same minimum standard. ${ }^{20}$

Hence, we can derive

Proposition 5: If firms cannot vary standards across markets, then, in equilibrium, regulators will set the globally optimum standard under national treatment.

Proof: From (8) and (9) the first order conditions for an optimum are

$$
\begin{array}{r}
\frac{\partial V_{1 N}}{\partial Q_{1 N}}+\frac{\partial R_{1 N}}{\partial Q_{1 N}}+\frac{\partial R_{2 N}}{\partial Q_{1 N}}-2 \frac{\partial C_{1 N}}{\partial Q_{1 N}}=0 \\
2 \frac{\partial V_{1 G}}{\partial Q_{1 G}}+2 \frac{\partial R_{1 G}}{\partial Q_{1 G}}+2 \frac{\partial R_{2 G}}{\partial Q_{1 G}}-4 \frac{\partial C_{1 G}}{\partial Q_{1 G}}=0 .
\end{array}
$$

These will clearly be satisfied by $Q_{1 N}=Q_{N}=Q_{G}$.

In this case, NT will result in higher welfare than MR. It follows that the case for MR in a symmetric, cross-hauling classical Cournot duopoly, rests upon firms being able to supply at different standards in the two markets.

\subsection{Monopoly/unbalanced trade with mutual recognition and inflexible quality standards}

As in the duopoly case, the setting of quality standards under MR is unaffected by making quality standards across the two countries inflexible.

The situation where there is only one producer, in one country but exporting to the other, and where the standard cannot vary across markets is the most complicated, because it introduces a game between the two regulators: the importing country regulator wants to set the highest standard consistent with the firm not exiting the market (as in Section 3, above). However, now, the issue of whether the firm will exit the market depends upon standards set in both countries.

To see this, consider a situation where the monopolist is located in country 2 . The importing country regulator 1 would like to set a minimum quality standard at $\widehat{Q}_{F}$, as in Figure 1, where the hat indicates we are in a game with invariant quality

\footnotetext{
${ }^{20}$ The analysis above needs to be slightly qualified, however. If regulator 2 sets a higher standard than $Q_{N}$, say $\widetilde{Q}$, then there is no incentive for regulator 1 to set a lower standard than $\widetilde{Q}$ (since a lower standard set unilaterally would have no effect), unless $\widetilde{Q}$ is so high that country 1 is better off foregoing profits from exports to the foreign market. Since this applies in reverse (to regulator 2 's response to regulator 1 ), it is conceivable that quality standards could become stuck in an equilibrium higher than $Q_{N}$.
} 
across the two markets. However, the exporting country regulator, 2, can now affect the firm's decision on whether to exit the market in country 1 , and so can affect $\widehat{Q}_{F}$, by deliberately setting a low minimum standard, $Q_{L}$, in its home market. The highest level of $\widehat{Q}_{F}$ which regulator 1 can set is the level where the firm is indifferent between selling to both markets at quality $\widehat{Q}_{F}$, or just selling to its domestic market at $Q_{L}$, which involves a lower fixed cost. This relationship will satisfy

$$
\begin{aligned}
2 R_{F}\left\{\widehat{Q}_{F}\right\}-R_{L}\left\{Q_{L}\right\} & =b\left(2 \widehat{Q}_{F}-Q_{L}\right) ; \\
2 \widehat{Q}_{F}^{v}-Q_{L}^{v} & =\frac{b\left(2 \widehat{Q}_{F}-Q_{L}\right)}{K_{1}\left(1-K_{3}\right)} .
\end{aligned}
$$

So long as $Q_{L}>Q_{U}$, lowering it will increase the firm's reservation profit - the level of profits it needs to make in both markets to induce it to accept selling into the export market. This means regulator 1 cannot set such a high level of $\widehat{Q}_{F}$.

The implication of this is that we face a bargaining situation: regulator 1 determines the quality $\widehat{Q}_{F}$ at which the good is sold in both markets but, as long as $Q_{L}>Q_{U}$, regulator 2 can set an upper limit on $\widehat{Q}_{F}$. Welfare in country 1 is maximised when $\widehat{Q}_{F}=Q_{F}$ as in equation (1.13). Welfare in country 2 is maximised when $\widehat{Q}_{F}=Q_{X}$, as in (6) (so long as regulator 1 can constrain regulator 2 by setting a value of $Q_{L}>Q_{U}$ ). Where both regulators have perfect certainty, we would expect a Nash bargaining outcome somewhere between their preferred values of $\widehat{Q}_{F}$.

Numerical simulations of this Nash bargaining model (compared to MR and to NT where quality is flexible) are shown in Appendix 2. The assumed bargaining weights are $50-50$. Note that no cases were found where $Q_{L}<Q_{U}$, so in all cases examined, quality is set by a Nash bargain over the range between $Q_{X}$ and $Q_{F}$ (as defined in Section 2, above). Also note that, in all cases examined, when quality is inflexible, combined welfare across the two countries is higher with NT than with MR. This is because the exporting/producing country, if unconstrained, would choose to set a suboptimal standard at $Q_{X}$ (which is in fact the standard which reigns under $\mathrm{MR}$ ), while the importing country wants to set a superoptimal standard at $Q_{F}$. The compromise standard under Nash bargaining with equal weights, is an improvement on either of those extremes. The overall loss to combined welfare from MR compared to NT is shown in Figure 7, below, and the exporting country is worse off, though the importing country is better off.

Figure 7: combined welfare gain NT compared to $M R$, with inflexible product quality.

Comparing Figure 7 to the case with flexible standards (Figure 3), in the inflexible case MR always produces a loss in welfare, whereas with flexible standards this 
is only the case where $\eta$ and $\beta$ are relatively high. However, again, MR performs less badly where $\beta$ is high (so the weighting placed on quality is less).

However, it is worth raising an alternative outcome: where the two regulators are less certain about each other's reaction functions, a standoff is possible in this game, in the form of a war of attrition, whereby trade is temporarily blocked because the two regulators set standards so far apart that the firm chooses not to export - each regulator waiting either for the other regulator to back down, or for an arbitrator such as the WTO to step in. This opens up a series of potentially interesting but complicated games, which would require another paper to analyse properly.

Another possibility is that the foreign firm cannot altogether avoid fixed costs by exiting the export market. In this case, the bargaining power of the importing country would be higher than indicated above, and Nash bargaining over national treatment would result in a higher quality standard, with lower overall welfare.

\section{Pure horizontal barriers}

The focus of this paper is primarily upon vertical standards - those which produce a measurable gain to consumer welfare. However, the issue of pure horizontal barriers is worth some discussion, since these are the focus of a significant literature on TBTs (e.g. Maskus and Wilson (eds., 2001)). A pure horizontal TBT (henceforth a HTBT) can only be applied where two firms are using different technology to get similar outcomes. The HTBT might be of a pure, cost-increasing variety (forcing the foreign firm to impose some form of adaptation on its produce in order to access the export market), or might even, in extremes, lead to exclusion of the foreign firm and imposition of a domestic monopoly.

If we consider a HTBT, this can be seen as raising the marginal cost of sales for the foreign firm by proportion $\tau$ (so that the marginal cost of the foreign good becomes $(1+\tau) M C$, while the domestic firm's marginal cost is just $M C)$. The cost $\tau M C$ is a resource cost: as such, regulator 1 would usually prefer to impose an equivalent tariff, since that raises revenue. Nevertheless, if tariffs are ruled out, or seen as too visible (and hence likely to provoke retaliation), then a HTBT may be applied.

Edwards (2009) examines the case of a Cournot duopoly with linear demand functions, and concludes that, where tariffs are ruled out, a HTBT will be chosen to exclude the foreign firm. Ironically, a smaller HTBT may not be attractive, since domestic welfare with linear demand is a quadratic function of $\tau$, and often decreases for a small value of $\tau$ before increasing. Nevertheless, some cautions must be added. First, a HTBT may not simply be a differentiable cost such as $\tau$ : there may be only 
one level of barrier available (the product has to meet local technical specifications), which may or may not end up excluding the foreign firm. Secondly, the welfare effects of the HTBT seem to be very specific to the functional form of the demand model. In addition, a HTBT which simply increases costs for the foreign firm would seem to be in breach of the WTO agreement (World Trade Organization (1995)), as cited at the beginning of this paper - and hence should not, in principle, be acceptable under NT. However,the WTO has had problems enforcing the agreement in such cases - as the discussion in Maskus and Wilson (eds., 2001) shows.

Consider the welfare effects for country 1 imposing a cost-raising HTBT of $\tau$ against firm 2. We stick to the case where marginal costs before the HTBT are equal for the two firms. The welfare effects in the importing country of the HTBT are: i) the loss of consumer surplus from raising firm 2's costs, $(\partial V / \partial Z)(\partial Z / \partial \tau)$ (this has a negative effect on welfare); ii) firm 1's share of the change in total profit from raising prices, $S_{1}(\partial \Pi / \partial Z)(\partial Z / \partial \tau)$ (this is positive when prices are below the collusive level, but declining); iii) the profit shift effect $\Pi\left(\partial S_{1} / \partial \tau\right)$, where $\Pi$ and $C$ are the joint profit and joint variable cost of the two firms. (Note that the analysis in this section assumes equal marginal costs before the HTBT is imposed.)

These effects are summarised in Table 4, below.

\begin{tabular}{||llll||}
\hline \hline Welfare effect & & Sign & $\begin{array}{l}\text { Effect } \\
\text { when } \tau=0\end{array}$ \\
i. Consumer surplus & $\frac{\partial V}{\partial Z} \frac{\partial Z}{\partial \tau}=-\frac{1}{(2+\tau)} \gamma \eta Z^{\eta}$ & - & $-\frac{1}{2} \gamma \eta Z^{\eta}$ \\
ii. Total profit effect & $S_{1} \frac{\partial \Pi}{\partial Z} \frac{\partial Z}{\partial \tau}=S_{1} \frac{1-(1+\tau) \eta}{(1-\eta)(2+\tau)^{2}} \gamma \eta Z^{\eta}$ & + & $\frac{1}{8} \gamma \eta Z^{\eta}$ \\
iii. Profit shift effect & $\Pi \frac{\partial S_{1}}{\partial \tau}=S_{1}^{2} \frac{1+\eta}{(2+\tau)(1+\tau-\eta)} \gamma \eta(1-\eta) Z^{\eta}$ & + & $\frac{1}{8}(1+\eta) \gamma \eta Z^{\eta}$ \\
Overall welfare effect & $-\frac{1}{(2+\tau)} \gamma \eta Z^{\eta}+S_{1} \frac{1-(1+\tau) \eta}{(1-\eta)(2+\tau)^{2}} \gamma \eta Z^{\eta}$ & & \\
& $+S_{1}^{2} \frac{1+\eta}{(2+\tau)(1+\tau-\eta)} \gamma \eta(1-\eta) Z^{\eta}$ & - & $\frac{\eta-2}{8} \gamma \eta Z^{\eta}$ \\
\hline \hline
\end{tabular}

Table 4: Welfare effects in country 1 of a HTBT against imports from country 2.

The right hand column evaluates the various marginal welfare effects when there is no initial HTBT, and finds that the net marginal effect is negative (since $\eta<1$ ). However, given the complexity of these functions, it is also necessary to investigate whether welfare might turn upwards at some point, as the HTBT is increased. Numerical simulations confirm this does not happen.

In a linear model, each marginal increase in the HTBT causes a constant shift in market share towards the domestic firm, and since prices rise as the HTBT is imposed, the profit shift is increasing. This causes the profit shift to outweigh the loss of consumer surplus, at least beyond a point (hence favouring total exclusion of 
the foreign firm). By contrast, with an isoelastic model, the shift in market share, $\partial S_{1} / \partial \tau$, tails off as $\tau$ increases, so that profit shift does not increase. Hence, the latter model does not favour horizontal protection.

Given the contradictory results from various demand functional forms, it is only safe to conclude that it is uncertain whether pure horizontal protection is likely to occur.

\section{Comparison with alternative oligopoly models}

Most previous studies of quality regulations ${ }^{21}$ have built on Shaked and Sutton's (1982) adaptation of a Hotelling linear framework to a vertical oligopoly. In this spatial representation of product differentiation, consumers differ in tastes, but have unitary demand ( 1 or zero units per head). The applications to minimum product standards in trade have all concentrated on a duopoly. Choosing a relatively restricted functional form (Lutz (1996), (2000), and Lutz and Baliamoune-Lutz (2003)), individual $i$ chooses whether or not to purchase one unit of the good $g$, and if so, whether to purchase from the upmarket provider, $u$, or the downmarket provider $d$. Willingness to pay is a linear function of the good's quality, depending on an individual taste parameter, $t_{i}$, assumed to follow a uniform, rectangular distribution. The individual chooses to purchase the commodity from one supplier by comparing the relative qualities to the difference in prices. Lutz (1996) also assumes total costs are a quadratic function of quality.

By setting an excessively wide quality difference, firms $u$ and $d$ can raise prices. A regulator can put downward pressure on prices by imposing a minimum standard on $d$, which narrows the gap between the firms (Das and Donnenfeld (1989)). Where there is an increasing product development cost, related to quality, then the minimum standard leads to lower prices per unit quality (Ronnen (1991)), and leads to increasing total sales. The lower quality regulator supplies at the minimum quality standard, while the higher-quality supplier overcomplies, in order to satisfy consumers with a higher taste for quality. A rise in the minimum quality causes both firms to raise quality and lower prices per unit quality (Ronnen (1991)). However, when there are two national regulators, the tendency is to raise the standard too high, shifting profit from the foreign firm to local consumers (who benefit from lower

${ }^{21}$ Das and Donnenfeld (1989), Crampes and Hollander (1995), Lutz (1996 and 2000), Lutz and Baliamoune-Lutz (2003) and Boom (1995) have applied the ShakedSutton model to international standard-setting, as do more recent studies by Jinji and Toshimitsu (2004) and Toshimitsu and Jinji (2008). There are too many examples of studies on standard-setting in the single-country Shaked-Sutton case to list here. 
price). On Lutz's (1996) functional form assumptions, MR results in the setting of optimum standards.

While studies have provided an important theoretical underpinning to mutual recognition, they suffer by assumption from the limitation of the unitary demand assumption, which rules out the classical oligopoly biases, which are the focus of this paper, by assumption. On the other hand, the classical model in this paper does not allow for consumer heterogeneity, and is also limited. Given the difficulty of constructing a generalised hybrid, it is probably sensible to regard the two setups as special cases, both offering insights, but which may be more or less applicable depending on the precise industry. In general, one might expect the Shaked-Sutton model to be more specifically applicable to lumpy durables such as cars or washing machines, while the classical oligopoly model applies best where purchases are non-lumpy. ${ }^{22}$ Where the quantity of the product purchased is determined by the purchase of a more expensive item (for example, the number of curtains purchased by a household depend on the number of windows in a house) then the ShakedSutton framework is likely to be favoured. By contrast, where the household loves (horizontal) variety, then a fall in prices will cause it to purchase more items of the good, as well as higher quality.

A recent paper of relevance is Costinot (2008), who compares regulatory regimes based upon national treatment and upon mutual recognition, in a two-country, twofirm framework, in the case of a good, the consumption of which creates an externality. Demand by each consumer is assumed to be unitary or zero. Costinot assumes a simple binary standard: goods are either high-polluting or low-polluting, which reduces the framework to that of a prisoner's dilemma game. Government imposition of a low polluting standard under national treatment leads to some direct benefits to consumers, but also to a reduction in the externality. Critically, under mutual recognition, there is a temptation to a 'race to the bottom' in standards, since national governments do not concern themselves with externalities in other countries. However, this is partially tempered by a Brander-Krugman type profit-shifting motive - similar to that identified in this paper. Since this profit-shifting effect (in both Costinot's paper and in this one) is only significant when consumers themselves prefer better quality goods, Costinot's important conclusion is that mutual recognition is only preferable where externalities are relatively small compared to direct consumer gains from improved quality. His paper also looks at horizontal (network

\footnotetext{
${ }^{22}$ However, even these cases may not be so clear-cut: many households in the West now own more than one automobile, while if quality is defined in terms of durability, then arguably a higher quality product will tend to substitute for less frequent purchases, so quality and quantity are substitutes.
} 
externality) barriers, which we do not directly consider here.

Some empirical studies (notably Arora and Cason (1995)) find over-compliance of environmental or other standards. While, at first sight, this is not easy to reconcile with theoretical models, ${ }^{23}$ a number of reasons have been suggested for this phenomenon (Harrington, 1988). It is worth bearing in mind that supplied quality may reflect labelling and transparency regulations, rather than just technical standards. ${ }^{24}$

\section{Conclusion}

Compared to studies to date, the classical oligopoly treats minimum standards as a response to different regulatory problems - in the latter, the case, the underprovision of quality by an oligopoly, while, in the former, the creation of an excessive differentiation between products. ${ }^{25}$ Which of these effects is the more important may depend on the industry in question. Nevertheless, there are similarities in the way the profit-shifting motive leads to strategic overregulation. The apparently contradictory finding on the effect on trade - which rises in the classical, Cournot oligopoly model, but falls in the spatial differentiation case - may simply reflect the difficulty of aggregating goods of different quality: in the classical duopoly model, the conclusion of rising trade relies upon weighting quantities by quality, while the spatial differentiation conclusion is based upon unadjusted quantities, so that the studies are not taking account of the different unit value of, say, Mercedes and Skodas.

A second interesting finding is that, when firms cannot vary the quality at which they supply the two markets, there is no distortion in standard-setting under national treatment with a symmetric, cross-hauling duopoly.

The more significant difference from the previous literature is the examination of the strategic biases present with unbalanced trade. In particular, this paper suggests the mutual recognition principle should not be applied indiscriminately as a condition of multilateral trade liberalisation regimes. Assessment of the welfare effects of harmonisation or mutual recognition should not be carried out on the assumption that regulations are purely cost-increasing. Indeed national variations in standards may genuinely reflect differences in national preferences with regard to risk, quality

\footnotetext{
${ }^{23}$ In the basic Cournot model, neither firm will overcomply, while in a Shaked-Sutton model, only one firm will overcomply.

${ }^{24}$ Arora and Cason's (1995) empirical finding that over-compliance is mainly a feature of industries with low concentration may be seen as consistent with this interpretation.

${ }^{25}$ It should be added that the classical oligopoly interpretation - regulation is needed to counteract undersupply of quality by big business - is more in tune with the stated objectives of most national product regulation.
} 
etc. A general mutual recognition principle could lead to its application in industries where one country dominates production, and there is a consequent danger of dilution of product standards for all importing countries. ${ }^{26}$

${ }^{26}$ This can, of course, be limited if the mutual recognition regime also includes an element of minimal standards centrally imposed across all countries, as happens, for example, under the European Union's mixed approach to the Single Market. 


\section{Appendix 1: Tables of the principal models}

Table 1.1: equations governing the equilibrium with a monopolist

\begin{tabular}{|c|c|}
\hline Solution for monopoly & Isoelastic/Cobb-Douglas form \\
\hline Unconstrained quality $\quad(1.1)$ & $Q_{U}=\left(\frac{1}{b} \frac{1-\beta}{\beta}\right)^{\beta} X_{U}$ \\
\hline Minimum unit cost & $c_{0}=\frac{1}{\beta}\left(\frac{1}{b} \frac{1-\beta}{\beta}\right)^{\beta-1}=\frac{1}{\beta}\left(\frac{X_{U}}{Q_{U}}\right)^{\frac{1-\beta}{\beta}}$. \\
\hline Q.a.output* & $\begin{array}{l}X=\Omega^{\frac{\beta}{1-\beta \eta}} Q^{\frac{v}{\eta}}, \text { where } \Omega=\beta \gamma \eta^{2}>0, \\
\text { and } v=\frac{(1-\beta) \eta}{1-\beta \eta}, \text { which lies between } 0 \text { and } 1 .\end{array}$ \\
\hline Revenue* & $R=k_{1} Q^{v}$, where $k_{1}=\gamma \eta \Omega^{\frac{\beta \eta}{1-\beta \eta}}>0$ \\
\hline Consumer surplus* & $V=k_{2} R$, where $k_{2}=\frac{1-\eta}{\eta}$ \\
\hline Costs* & $C=k_{3} R-b Q$, where $k_{3}=\beta \eta$. \\
\hline Marginal cost* & $M C=\frac{\partial C}{\delta X}=\frac{1}{\beta}\left(\frac{X}{Q}\right)^{\frac{1-\beta}{\beta}}$ \\
\hline Profit* & $\Pi=\left(1-k_{3}\right) k_{1} Q^{v}-b Q$ \\
\hline Profit-maximising quality (1.9) & $Q_{U}^{1-v}=\left(1-k_{3}\right) v \frac{k_{1}}{b}$ \\
\hline Welfare (domestic firm)* (1.10) & $W=\left(1+k_{2}-k_{3}\right) k_{1} Q^{v}-b Q$ \\
\hline maximum when* $(1.11)$ & $Q_{G}^{1-v}=Q^{1-v}=\left(k_{2}+1-k_{3}\right) v \frac{k_{1}}{b}$. \\
\hline Welfare (firm is foreign)* ${ }^{*} \quad(1.12)$ & $W_{F}=k_{2} k_{1} Q^{v}$, monotonically increasing wrt $Q$. \\
\hline Zero profit* & $\left(1-k_{3}\right) k_{1} Q^{v}=b Q,==>Q_{F}^{1-v}=\left(1-k_{3}\right) \frac{k_{1}}{b}$ \\
\hline Unadjusted output* & $\begin{array}{l}Y=\Omega^{\frac{1}{1-\beta \eta}} Q^{\frac{-(1-\beta)^{2}}{\beta(1-\beta \eta)}} \\
\Rightarrow \frac{\partial Y}{\partial Q}<0 . \text { Unadjusted output falls. }\end{array}$ \\
\hline
\end{tabular}

$27 *$ denotes quality is regulated 
Table 1.2: equations governing the equilibrium with a cross-hauling duopoly

\begin{tabular}{|c|c|}
\hline Duopoly with NT & isoelastic/Cobb-Douglas functional form \\
\hline Unregulated quality (2.1) & $\bar{Q}_{U}=\Psi^{\frac{1}{1-\eta}} 2^{\frac{2-\eta}{\eta-1}}\left(\frac{1}{b} \frac{1-\beta}{\beta}\right)^{\frac{1}{1-v}}$, where $\Psi=\beta \gamma \eta(1+\eta)>0$ \\
\hline Regulated output* (2.2) & $Z=\Psi^{\frac{\beta}{1-\beta \eta}} 2^{\frac{1-2 \beta}{1-\beta \eta}} Q^{\frac{v}{\eta}}=Z_{U}\left(\frac{Q_{R}}{Q_{U}}\right)^{\frac{v}{\eta}}$ \\
\hline Revenue of firm $1^{*}(2.3)$ & $R_{1}=K_{1} Q^{v}$, where $K_{1}=\left(\frac{\gamma \eta}{2}\right) \Psi^{\frac{\beta \eta}{1-\beta \eta}} 2^{\frac{(1-2 \beta) \eta}{1-\beta \eta}}$. \\
\hline Cons surp in ctry $1^{*}(2.4)$ & $V_{1}=K_{2} R_{1}$, where $K_{2}=2 \frac{1-\eta}{\eta}$ \\
\hline Firm 1's costs* & $C_{1}=K_{3} R_{1}-b Q_{1}$, where $K_{3}=\beta \frac{1+\eta}{2}$. \\
\hline $\begin{array}{l}\text { Welf in country } 1^{*}(2.6) \\
\text { maximised when } *(2.7)\end{array}$ & $\begin{array}{l}W=V_{1}+R_{1}-C_{1}=\left(1+K_{2}-K_{3}^{2}\right) K_{1} Q^{v}-b Q_{1} . \\
Q_{F}^{1-v}=\left[K_{2}+1-K_{3}\right] v \frac{K_{1}}{b} .\end{array}$ \\
\hline $\begin{array}{c}\text { Global welfare* }(2.8) \\
\text { maximised when* }(2.9)\end{array}$ & $\begin{array}{l}W_{G}=V_{1}+2 R_{1}-2 C_{1}=\left(1+2 K_{2}-2 K_{3}\right) K_{1} Q_{G}^{v}-2 b Q_{1 G} \\
Q_{G}^{1-v}=\left[\frac{K_{2}}{2}+1-K_{3}\right] v \frac{K_{1}}{b} .\end{array}$ \\
\hline 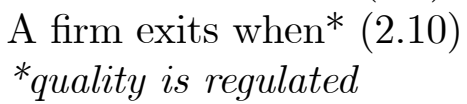 & $\left(1+K_{2}-K_{3}\right) K_{1} Q_{0}^{v}-b Q_{0}=0 \Longrightarrow Q_{0}^{1-v}=\left(1-K_{3}\right) \frac{K_{1}}{b}$ \\
\hline
\end{tabular}




\section{Numerical solutions of national treatment and mutual recognition in a monopoly case}

Changes in welfare are calculated as proportions of total global welfare in the globally optimum standards case. Two sets of scenarios are looked at: first, where standards are flexible across the two countries, and secondly where standards are inflexible.

\section{References}

\section{References}

[29] Arora, S. and T.Cason (1995), 'An Experiment in Voluntary Environmental Regulation: Participation in EPA's 33/50 Program,' Journal of Environmental Economics and Management, 28, 271-86.

[29] Boom, A. (1995), 'Asymmetric International Minimum Quality Standards and Vertical Differentiation,' Journal of Industrial Economics, 43 (1), 101-109.

[29] Brander, J.A. (1981), 'Intra-industry trade in identical products,' Journal of International Economics, 11, 1-14.

[29] Brander, J.A. (1995), 'Strategic Trade Policy,' NBER Working Paper 5020, reprinted in GM Grossman \& K. Rogoff (eds.) Handbook of International Economics III, Elsevier.

[29] Brander, J. and B. Spencer (1985), 'Export Subsidies and Market Share Rivalry,' Journal of International Economics 18, 83-100.

[29] Costinot, A. (2008), 'A Comparative Institutional Analysis of Agreements on Product Standards,' Journal of International Economics 75, 197-213.

[29] Crampes, C, and A. Hollander (1995), 'Duopoly and quality standards,' European Economic Review, 39(1), 71-82

[29] Das, S.P. and S.Donnenfeld (1989), 'Oligopolistic Competition and International Trade: Quantity and Quality Restrictions,' Journal of International Economics 27 (3-4), 299-318.

[29] Edwards, T.H. (2009), 'Tariffs, Horizontal Regulatory Standards and Protection Against Foreign Competitors,' Global Economy Journal 9(2), Article 2. 
Table A2.1 National treatment compared to mutual recognition with flexible standards: exporting country

\begin{tabular}{lrrrrrrrrr}
\multicolumn{1}{l}{ Percent } & & & & & & & & \\
$\eta$ & 0.1 & 0.2 & 0.3 & 0.4 & 0.5 & 0.6 & 0.7 & 0.8 & 0.9 \\
0.1 & -1.8 & -2.1 & -2.6 & -3.1 & -3.6 & -4.3 & -5.1 & -6.0 & -7.2 \\
0.2 & -3.3 & -4.0 & -4.7 & -5.5 & -6.5 & -7.7 & -9.1 & -10.8 & -13.1 \\
0.3 & -4.7 & -5.5 & -6.4 & -7.5 & -8.8 & -10.4 & -12.3 & -14.7 & -17.8 \\
0.4 & -5.9 & -6.8 & -7.8 & -9.1 & -10.5 & -12.4 & -14.7 & -17.6 & -21.6 \\
0.5 & -7.0 & -7.9 & -8.9 & -10.2 & -11.8 & -13.8 & -16.3 & -19.7 & -24.5 \\
0.6 & -7.9 & -8.7 & -9.7 & -11.0 & -12.5 & -14.5 & -17.2 & -20.9 & -26.4 \\
0.7 & -8.8 & -9.5 & -10.3 & -11.4 & -12.8 & -14.7 & -17.2 & -21.0 & -27.2 \\
0.8 & -9.5 & -10.0 & -10.7 & -11.5 & -12.6 & -14.1 & -16.4 & -19.9 & -26.4 \\
0.9 & -10.1 & -10.4 & -10.8 & -11.2 & -11.9 & -12.8 & -14.3 & -16.8 & -22.5
\end{tabular}

Table A2.2 National treatment compared to mutual recognition with flexible standards: importing country

$\begin{array}{lrrrrrrrrr} & \text { Percent } & & & & & & & & \\ \eta & 0.1 & 0.2 & 0.3 & 0.4 & 0.5 & 0.6 & 0.7 & 0.8 & 0.9 \\ 0.1 & & & & & & & & & \\ 0.2 & 3.3 & 3.4 & 3.4 & 3.3 & 3.2 & 3.0 & 2.6 & 2.1 & 1.4 \\ 0.3 & 6.1 & 6.2 & 6.2 & 6.1 & 5.9 & 5.5 & 4.9 & 4.0 & 2.7 \\ 0.4 & 8.6 & 8.7 & 8.7 & 8.6 & 8.3 & 7.8 & 7.0 & 5.8 & 3.9 \\ 0.5 & 10.7 & 10.8 & 10.8 & 10.7 & 10.4 & 9.9 & 9.0 & 7.5 & 5.2 \\ 0.6 & 12.6 & 12.7 & 12.8 & 12.7 & 12.4 & 11.8 & 10.9 & 9.3 & 6.5 \\ 0.7 & 14.4 & 14.4 & 14.5 & 14.4 & 14.2 & 13.7 & 12.8 & 11.2 & 8.1 \\ 0.8 & 15.9 & 16.0 & 16.0 & 16.0 & 15.8 & 15.5 & 14.8 & 13.3 & 10.0 \\ 0.9 & 17.3 & 17.3 & 17.4 & 17.4 & 17.4 & 17.2 & 16.7 & 15.6 & 12.6 \\ & 18.5 & 18.6 & 18.6 & 18.7 & 18.7 & 18.7 & 18.6 & 18.1 & 16.2\end{array}$

Table A2.3 National treatment compared to mutual recognition with flexible standards: both countries Per cent

$\begin{array}{lrrrrrrrrr}\beta & 0.1 & 0.2 & 0.3 & 0.4 & 0.5 & 0.6 & 0.7 & 0.8 & 0.9 \\ \eta & & & & & & & & & \\ 0.1 & 1.5 & 1.2 & 0.8 & 0.2 & -0.5 & -1.3 & -2.4 & -3.9 & -5.8 \\ 0.2 & 2.8 & 2.2 & 1.5 & 0.6 & -0.6 & -2.2 & -4.2 & -6.8 & -10.4 \\ 0.3 & 3.9 & 3.2 & 2.3 & 1.0 & -0.5 & -2.6 & -5.3 & -8.9 & -13.9 \\ 0.4 & 4.8 & 4.0 & 3.0 & 1.7 & -0.1 & -2.5 & -5.7 & -10.1 & -16.4 \\ 0.5 & 5.7 & 4.9 & 3.8 & 2.5 & 0.6 & -1.9 & -5.4 & -10.4 & -18.0 \\ 0.6 & 6.4 & 5.7 & 4.7 & 3.4 & 1.7 & -0.8 & -4.4 & -9.7 & -18.3 \\ 0.7 & 7.1 & 6.5 & 5.7 & 4.6 & 3.1 & 0.8 & -2.5 & -7.8 & -17.2 \\ 0.8 & 7.8 & 7.3 & 6.7 & 5.9 & 4.8 & 3.1 & 0.4 & -4.3 & -13.8 \\ 0.9 & 8.4 & 8.2 & 7.9 & 7.4 & 6.8 & 5.8 & 4.3 & 1.2 & -6.3\end{array}$


Table A2.4 National treatment compared to mutual recognition with inflexible standards: exporting country

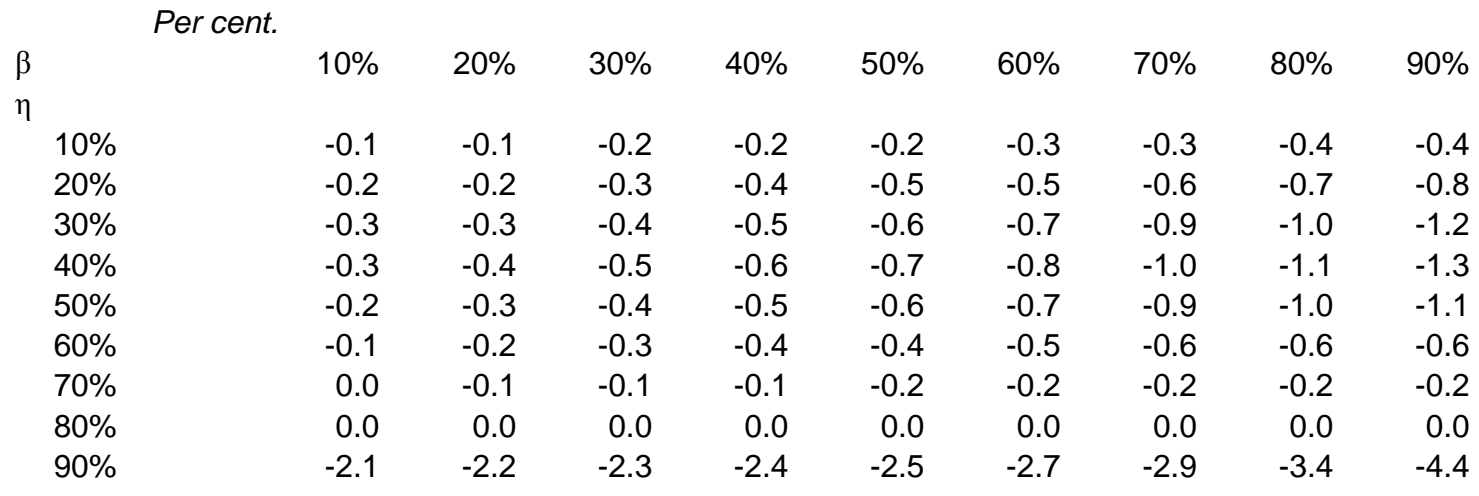

Table A2.5 National treatment compared to mutual recognition with inflexible standards: importing country

\begin{tabular}{|c|c|c|c|c|c|c|c|c|c|}
\hline \multicolumn{10}{|c|}{ Percent } \\
\hline$\beta$ & $10 \%$ & $20 \%$ & $30 \%$ & $40 \%$ & $50 \%$ & $60 \%$ & $70 \%$ & $80 \%$ & $90 \%$ \\
\hline \multicolumn{10}{|l|}{$n$} \\
\hline $10 \%$ & 0.9 & 0.9 & 0.9 & 0.9 & 0.9 & 0.9 & 0.8 & 0.7 & 0.5 \\
\hline $20 \%$ & 1.6 & 1.7 & 1.7 & 1.8 & 1.7 & 1.7 & 1.6 & 1.3 & 1.0 \\
\hline $30 \%$ & 2.1 & 2.3 & 2.4 & 2.4 & 2.4 & 2.3 & 2.2 & 1.9 & 1.3 \\
\hline $40 \%$ & 2.4 & 2.6 & 2.7 & 2.8 & 2.8 & 2.8 & 2.6 & 2.2 & 1.6 \\
\hline $50 \%$ & 2.4 & 2.6 & 2.8 & 2.9 & 3.0 & 2.9 & 2.7 & 2.4 & 1.7 \\
\hline $60 \%$ & 1.9 & 2.2 & 2.5 & 2.6 & 2.7 & 2.6 & 2.5 & 2.1 & 1.5 \\
\hline $70 \%$ & 1.1 & 1.4 & 1.6 & 1.8 & 1.8 & 1.8 & 1.7 & 1.4 & 1.0 \\
\hline $80 \%$ & 0.3 & 0.4 & 0.6 & 0.6 & 0.7 & 0.7 & 0.6 & 0.5 & 0.3 \\
\hline $90 \%$ & 8.2 & 8.2 & 8.2 & 8.2 & 8.2 & 8.2 & 8.2 & 8.0 & 7.2 \\
\hline
\end{tabular}

Table A2.6 National treatment compared to mutual recognition with inflexible standards: both countries Percent

$\begin{array}{lrrrrrrrrr}\beta & 10 \% & 20 \% & 30 \% & 40 \% & 50 \% & 60 \% & 70 \% & 80 \% & 90 \% \\ \eta & & & & & & & & & \\ 10 \% & 0.8 & 0.8 & 0.8 & 0.7 & 0.7 & 0.6 & 0.5 & 0.3 & 0.1 \\ 20 \% & 1.4 & 1.4 & 1.4 & 1.4 & 1.3 & 1.1 & 0.9 & 0.6 & 0.1 \\ 30 \% & 1.9 & 1.9 & 1.9 & 1.9 & 1.8 & 1.6 & 1.3 & 0.8 & 0.2 \\ 40 \% & 2.1 & 2.2 & 2.3 & 2.3 & 2.2 & 2.0 & 1.6 & 1.1 & 0.4 \\ 50 \% & 2.1 & 2.3 & 2.4 & 2.4 & 2.4 & 2.2 & 1.9 & 1.4 & 0.7 \\ 60 \% & 1.8 & 2.0 & 2.2 & 2.3 & 2.2 & 2.1 & 1.9 & 1.5 & 0.9 \\ 70 \% & 1.1 & 1.3 & 1.5 & 1.6 & 1.7 & 1.6 & 1.5 & 1.2 & 0.8 \\ 80 \% & 0.3 & 0.4 & 0.5 & 0.6 & 0.6 & 0.6 & 0.6 & 0.4 & 0.3 \\ 90 \% & 6.1 & 6.0 & 6.0 & 5.9 & 5.8 & 5.6 & 5.2 & 4.6 & 2.8\end{array}$


[29] Harrington, W. (1988), 'Enforcement Leverage When Probabilities Are Restricted,' Journal of Public Economics, 37, 229-253.

[29] Irwin, D.A. and Pavcnik, N. (2004), 'Airbus versus Boeing Revisited: International Competition in the Aircraft Market,' Journal of International Economics, $64(2), 223-245$.

[29] Jinji, N. and T.Toshimitsu (2004), 'Minimum Quality Standards under Asymmetric Duopoly with Endogenous Quality Ordering: A Note,' Journal of Regulatory Economics 26:2, 189-99.

[29] Lutz, S. (1996), 'Vertical Product Differentiation, Quality Standards and International Trade Policy,' CEPR Discussion Paper No 1443, London.

[29] Lutz, S. (2000), 'Trade Effects of Minimum Quality Standards with and without Deterred Entry,' Journal of Economic Integration 15(2), 314-44.

[29] Lutz, S. and M.Baliamoune-Lutz (2003), 'Mutual Recognition of National Minimum Quality Standards may Support International Convergence,' Journal of Industry, Competition and Trade, Springer, 3(4), 293-311.

[29] Maskus, K.E. and J.S.Wilson (eds 2001), 'Quantifying the Impact of Technical Barriers to Trade,' Michigan University Press. Chs 1 and 2 by the editors.

[29] Neary, J.P. (1994), 'Cost Asymmetries in International Subsidy Games: Should Governments Help Winners or Losers?' Journal of International Economics 37, 197-218.

[29] Nielsen, C. and K. Anderson (2001), 'GMOs, Trade Policy and Welfare in Rich and Poor Countries,' in Maskus and Wilson, op cit.

[29] OECD (1999), 'Regulatory Reform and International Standardisation', Paris.

[29] Pavcnik, N. (2002), 'Trade Disputes in the Commercial Aircraft Industry,' World Economy, 25(5), 733-751.

[29] Ronnen, U. (1991), 'Minimum Quality Standards, Fixed Costs, and Competition,' RAND Journal of Economics, 22(4), 490-504.

[29] Shaked, A. and J.Sutton (1982), 'Relaxing Price Competition Through Product Differentiation,' Review of Economic Studies, 49, 3-13. 
[29] Sheshinski, E. (1976), 'Price, Quantity and Quality Regulation in a Monopoly Situation,' Economica XLIII 127-137.

[29] Spence, A.M. (1975), 'Monopoly, Quality and Regulation,' Bell Journal of Economics VI (1975), 417-429.

[29] Sturm, D.M. (2006), 'Product Standards, Trade Disputes, and Protectionism,' Canadian Journal of Economics, 39 (2), 564-581.

[29] Swann, P., P.Temple and M.Shurmer (1996), 'Standards and Trade Performance: The UK Experience,' Economic Journal 106: 1297-1313.

[29] Sykes, A.O. (1995), 'Product Standards for Internationally Integrated Goods Markets,' Brookings Institution, Washington D.C.

[29] Toshimitsu, T. and N.Jinji (2008), 'A Note on Strategic Trade Policy and Endogenous Quality Choice,' Review of International Economics, 16 (1), 173-85.

[29] World Trade Organization (1995), 'Agreement on Technical Barriers to Trade,' from the Uruguay Round.

T.Huw Edwards

School of Business and Economics

Loughborough University

Ashby Road

Loughborough

United Kingdom

E-mail: T.H.Edwards@lboro.ac.uk 